This item was submitted to Loughborough's Research Repository by the author.

Items in Figshare are protected by copyright, with all rights reserved, unless otherwise indicated.

\title{
Wear in large diameter grouted connections for offshore wind energy converters
}

PLEASE CITE THE PUBLISHED VERSION

\section{PUBLISHER}

(C) Research Publishing Services

\section{VERSION}

AM (Accepted Manuscript)

\section{PUBLISHER STATEMENT}

This work is made available according to the conditions of the Creative Commons Attribution-NonCommercialNoDerivatives 4.0 International (CC BY-NC-ND 4.0) licence. Full details of this licence are available at: https://creativecommons.org/licenses/by-nc-nd/4.0/

\section{LICENCE}

CC BY-NC-ND 4.0

\section{REPOSITORY RECORD}

Dallyn, Paul A., Ashraf El-Hamalawi, and Alessandro Palmeri. 2019. "Wear in Large Diameter Grouted Connections for Offshore Wind Energy Converters”. figshare. https://hdl.handle.net/2134/16301. 


\title{
Wear in Large Diameter Grouted Connections for Offshore Wind Energy Converters
}

\author{
Paul Dallyn; Ashraf El-Hamalawi; Alessandro Palmeri \\ Civil and Building Engineering \\ Loughborough University, Leicestershire, England \\ P.A.Dallyn@lboro.ac.uk;A.El-hamalawi@lboro.ac.uk; A.Palmeri@lboro.ac.uk \\ Robert Knight; Andrew Morris \\ Civil Engineering \\ E.ON New Build and Technology, Nottingham, England \\ Bob.Knight@eon.com; Andy.P.Morris@eon.com
}

\begin{abstract}
The paper provides a critical appraisal of the events surrounding the unexpected settlement of large-diameter monopile foundations for offshore wind energy converters, and will detail experimentation that is to be undertaken to determine the extent of the wear failure mode in such structures. The potential for wear deterioration at the grout-steel interface has been caused by the lack of axial load transfer of the grout and steel and so relative movement between the grout and steel is occurring. Hence, a better understanding of this phenomenon is of key importance to determine the long term integrity of the structure. The remedial solution currently favoured within industry consists of the installation of elastomeric bearings, which however may further exasperate the wear due to its lower stiffness than steel contact currently occurring, also because of the presence of water in the grouted connection. The aim of the testing is therefore to identify the risk to offshore foundation integrity due to grout wear under conditions typically observed during life-time operation of offshore wind turbines. The main factors influencing the wear rate of grout will be identified, and the possibility to define indicators for the integrity of the grout that could be used for offshore inspection will be also considered.
\end{abstract}

\section{Introduction}

During summer 2009 rumours in the offshore wind energy converter (OWEC) industry suggested that the offshore wind farm Egmond aan Zee was exhibiting unexpected settlements in the grouted connection between the monopile and transition piece. This event culminated in September 2009 with Det Norske Veritas (DNV) issuing a letter to offshore wind farm operators and other stakeholders, highlighting concerns that there may be insufficient axial capacity of grouted joints.

The original design concept of a sleeved grouted joint had been used for over 650 installed monopiles for several offshore European wind farms, representing around 60 percent of all offshore foundations installed in Europe. The design details of the joint and the detailed design of the temporary support brackets used during grouting vary between wind farms, and a typical example is shown in Fig. 1. All of these foundations are at risk of settlements that 
may result in load being unintentionally transferred through temporary installation and alignment brackets known as jacking brackets. The fatigue life of certain elements of these structures may now be potentially less than their original design life.
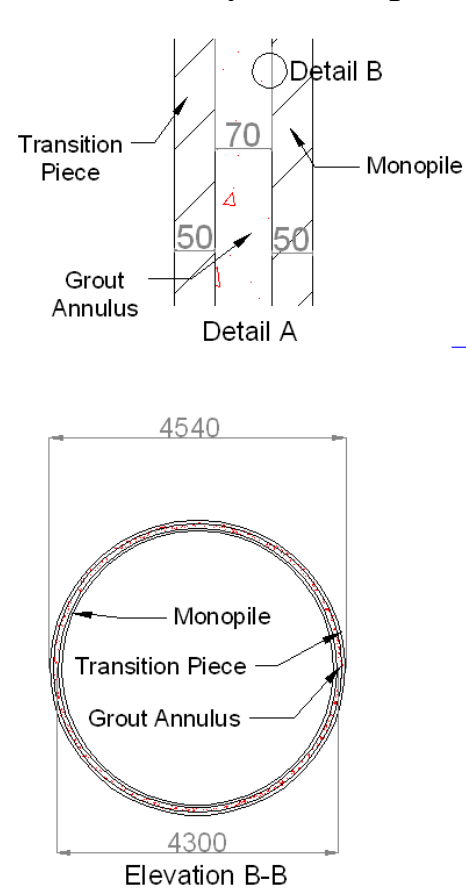

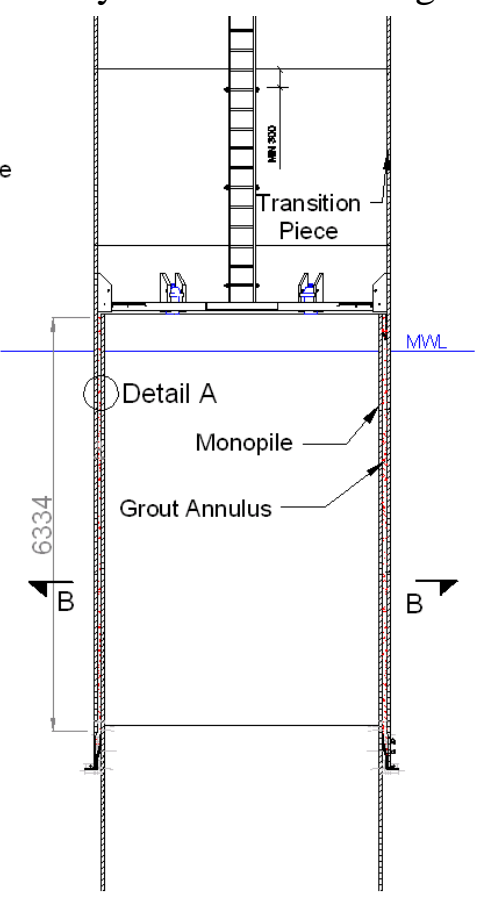

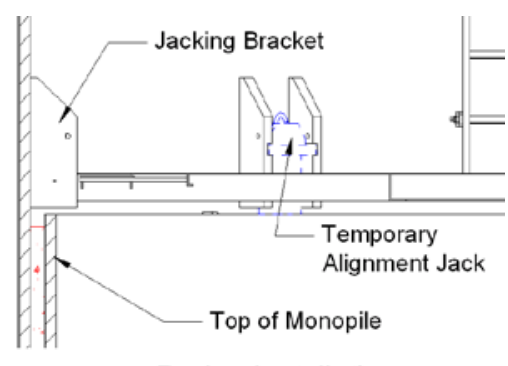

During Installation

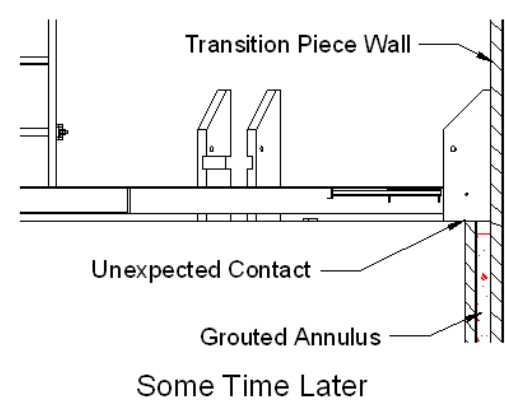

Figure 1: Typical grouted connection general arrangement

The literary review undertaken as part of ongoing research, and summarised in the next section, has revealed that there is a lack of detailed knowledge of the behaviour of the grouted connections, not only for the scale and size of actual structures, but also under the loading and environmental conditions of operation. Current understanding based on site inspections, is that settlement has occurred, therefore indicating insufficient axial capacity of the grouted connection, resulting in the jacking brackets coming into contact with the top of the monopile after an unknown period of time. Operators have observed that this settlement is mobilised after an initial large overturning moment occurs shortly after commissioning and operation of the turbines, with relative displacement between the transition piece and monopile occurring during a large change in overturning moment. The initial axial captivity is developed as a result of surface irregularities between the grout and the steel creating a shear resistance. As a result of the overturning moment a compressive force is created between the grout and the steel which increases the axial capacity of the connection. This overturning moment also creates an axial force as a result of the lever arm around the centre of the connection's diameter, which at some point overcomes the axial capacity resulting in relative displacement between the steel and the grout.

Based on current knowledge, the fatigue life predictions are that fatigue crack initiation may occur at the toes of the partial penetration jacking bracket fillet welds before the end of the turbine design life of 20 years. There is therefore a need to undertake remedial work to ensure the original design life is maintained and the risk of structural damage is mitigated. Potential remedial solutions that can extend the life of the transition piece joint to acceptable levels without compromising the integrity of the existing structure are being proposed by industry. The vast majority of the suggested solutions require the installation of elastomeric bearings to transfer the axial load from the transition piece to the monopile, and as a result of relative movements between the grout and steel surfaces will continue to occur in combination with large compressive stresses, which is potentially a very severe condition for 
$10^{\text {th }}$ International Conference on Advances in Steel Concrete Composite and Hybrid Structures

Singapore, 2 - 4July 2012

the connection. These proposals to date only address axial capacity of the connections and so still rely on grout integrity to transfer the bending moments from the tower/transition piece to the monopile.

As well as this, water ingress has been reported at some sites and at others evidence of water entrapment within the grouted region. With the combination of these factors grout wear could be a significant issue for the long term life time of the foundation. Currently the high strength grout has only been tested for compressive strength and fatigue by manufacturers. If wear is occurring and the water ingress provides transportation for the broken down grout material, gaps may form between the grout and outer face of the monopile. This may lead to a lack of fit and significant dynamic impacts on the structure as the tower moves/oscillates. There is also a risk that the overall length of the grouted connection reduces, reducing the lever arm over which the loading is transferred from the transition piece to the monopile and therefore increasing the stress within the grout and the steel.

Last but not least; understanding of the performance of the grout-steel interface over longterm service operation is not fully comprehensive. Testing has been carried out with joint industry projects (Det Norske Veritas, 2010), but this has not considered some areas that have raised concern, e.g. grout wear and water ingress. It is therefore necessary to improve our understanding of the wear failure mode in such situations, hence experimental testing will be undertaken as part of our current research to determine its extent under conditions that are representative of those seen by a typical operational foundation. After a brief review of the research questions posed by the current state of theoretical and practical knowledge in the field, the second part of the paper will detail the experimental setup and the testing protocol which will be used to tackle the problem.

\section{Position of the Problem}

Grouted tubular connections have been used extensively and successfully in the offshore oil and gas industry for decades and as such design of offshore wind energy converter foundation structures has evolved from codes such as American Petroleum Industry (API) (American Petroleum Institute, 2000) and International Organization for Standardization (ISO) 19902 (International Organization for Standardization, 2007). The experience these codes are based on are not entirely applicable to OWEC foundation structures as the sizes they are related to are significantly smaller and loading conditions considerably different. As a result, various standards have been produced that incorporate the experience from onshore and offshore wind projects and the oil and gas industry such as International Electrotechnical Commission (IEC) 61400-3 (International Electrotechnical Commission, 2005), Germanischer Lloyd (GL) 2005 (Germanischer Lloyd, 2005) and Det Norske Veritas (DNV) OS-J101 (Det Norske Veritas, 2004). Although these codes have been based on laboratory testing (Anderson and Peterson, 2004; Klose et al., 2008; Anders and Lohaus, 2008; Schaumann and Wilke, 2005), they only consider single loading conditions i.e. axial or bending, not the combination of both as would be found in operation. It has also been demonstrated that scale effects have a considerable influence, as small scale specimens are relatively stronger than the larger samples they should represent (Lotsberg, 2010).

Another issue was that the design equations for the axial capacity of the grout used in DNV and ISO were based on experimental data by Billington and Tebbett (1980) and Lamport and Jirsa (1986), but tests were only conducted on grouts with strengths up to $80 \mathrm{MPa}$, with diameter $(d)$ to thickness $(t)$ ratios up to 30 and thickness of grout up to $40 \mathrm{~mm}$, compared to actual strengths of about $120 \mathrm{MPa}, d / t$ ratios of around 40 and thickness up to $100 \mathrm{~mm}$. As pointed out by Klose et al. (2008) fatigue assessment for the grout, is currently based on 
concepts originally developed for concrete structures and an explicit S-N curve for high strength grouts is not available, which can therefore lead to fatigue calculations that can vary by a factor of 100 due to the slight gradient of the curve (Schaumann and Keindorf, 2008). More precisely, the adopted code of practice S-N curve is based on the CEB-FIP Model Code 1990 (FIP-CEB, 1990), however this curve has been derived with low-cycle fatigue experiments in comparison to the high number of cycles experienced in an OWEC's lifetime. The curve is also representative of uniaxial compression, and so the influence of tension, shear and biaxial loadings on fatigue are not taken into account. The design codes also recommend fatigue calculations based on linear damage accumulation, but it has been demonstrated by Anders and Lohaus (2008) and Schaumann and Keindorf (2008) that this is not appropriate for high strength grouts, as grout cracking is neglected in fatigue predictions. Grünberg et al. (2005) have shown that this approach could lead to unsafe and/or uneconomical design as the damage accumulation process is significantly changed by multiple load levels due to cracking altering the material behaviour. They concluded that a fracture energy approach is more representative of true behavior and that simultaneous tensions loading can lead to a significant decrease of the uniaxial fatigue capacity.

It is hypothesised from onsite displacement monitoring that any initial bond is soon overcome after commissioning when the foundation experiences its first large load event from the operational turbine. Once this initial 'bond' is broken, the axial capacity becomes a function of stiffness, material properties, surface irregularities, coefficient of friction and horizontal compressive load and so these properties become important. Recent studies have also paid attention to the severe environmental conditions in operation, e.g the reduction of the groutsteel coefficient of friction due to the ingress of sea water (Schaumann et al. 2010), which is likely to reduce the post-bond axial capacity of the connection (Det Norske Veritas, 2010). There is also the possible risk of water flow providing a transportation medium for fragmented or ground grout or cyclic moisture movement, which in turn would affect the fatigue capacity through microcraking, as demonstrated by Berndt (2010). The effects of slenderness of the transition piece and pile walls on the containment of grout, due to ovalisation and shape deformation under loading, have been also mentioned in the recent papers (Schaumann, 2007 and Schaumann et al., 2010). Veludo et al. (2012) have experimentally demonstrated that the initial bond strength between grout and steel has a very strong positive correlation to the radial confinement for axially loaded micro-piles.

To the best of our knowledge, no attempt has been made to experimentally quantify all these effects for OWEC foundations, and this constitutes the main motivation of this study and to ensure the long-term integrity of the foundation. Developers have, for economical and production reasons sought in recent years the installation of bigger turbines into deeper waters, resulting in foundations increasing in size. The design of the foundations was based on the hypothesis that the surface irregularities of the steel in the connection were proportional to the diameter of the pile. However, standard manufacturing and finishing techniques are used for the production of the steel, with just the rolled diameter changing, and thus the surface irregularity is likely to remain similar between pile diameters, as recently shown by Losberg (2010) for the foundations with observed settlements.

Recent testing on the axial capacity, both statically and with dynamic relative movements between the grout and steel by Det Norske Veritas (2011), have shown that increasing the number of load cycles significantly reduces the strength of the connection, but testing was only performed on three small scale samples, and so the practical significance of these findings is limited. Surface condition was representative with preparation to Sa2 according to ISO 8510, but surface deterioration due to free corrosion as seen on the steel surfaces during 
storage and installation, which can be up to a year, was not considered. The testing regime in terms of frequency and amplitude of movements also lacks relation to offshore operational conditions seen.

\section{Experimentation}

The aim of this project is to identify the risk to offshore foundation integrity due to grout wear under conditions typically seen during life time operation of offshore wind turbines, with and without elastomeric bearings. As a necessary first step to achieve this, an experimental protocol has been designed to simulate realistically such challenging conditions. The next two sections details the testing apparatus and a summary of methodology underpinning the experimentation.

\subsection{Apparatus}

The test apparatus shown in Fig. 2 has been designed in order to allow large lateral compressive force on the grout/steel surface while being able to dynamically control axial displacement.

The finite element analysis of an operational wind turbine structure under the fatigue or ultimate limit state loading scenarios indicates compressive stresses within the grout of between 6 to $14 \mathrm{MPa}$, respectively, if averaged over the bottom or top $500 \mathrm{~mm}$ of the grouted connection. The test rig has been therefore designed to produce up to $6 \mathrm{MPa}$ compressive stress on the grout, while being able to achieve a significant relative displacement between the steel and grout. The vertical load capacity of the SCHENCK testing rig used in the experimental campaign is $160 \mathrm{kN}$, which will allow testing samples of size $150 \times 150 \mathrm{~mm}$.

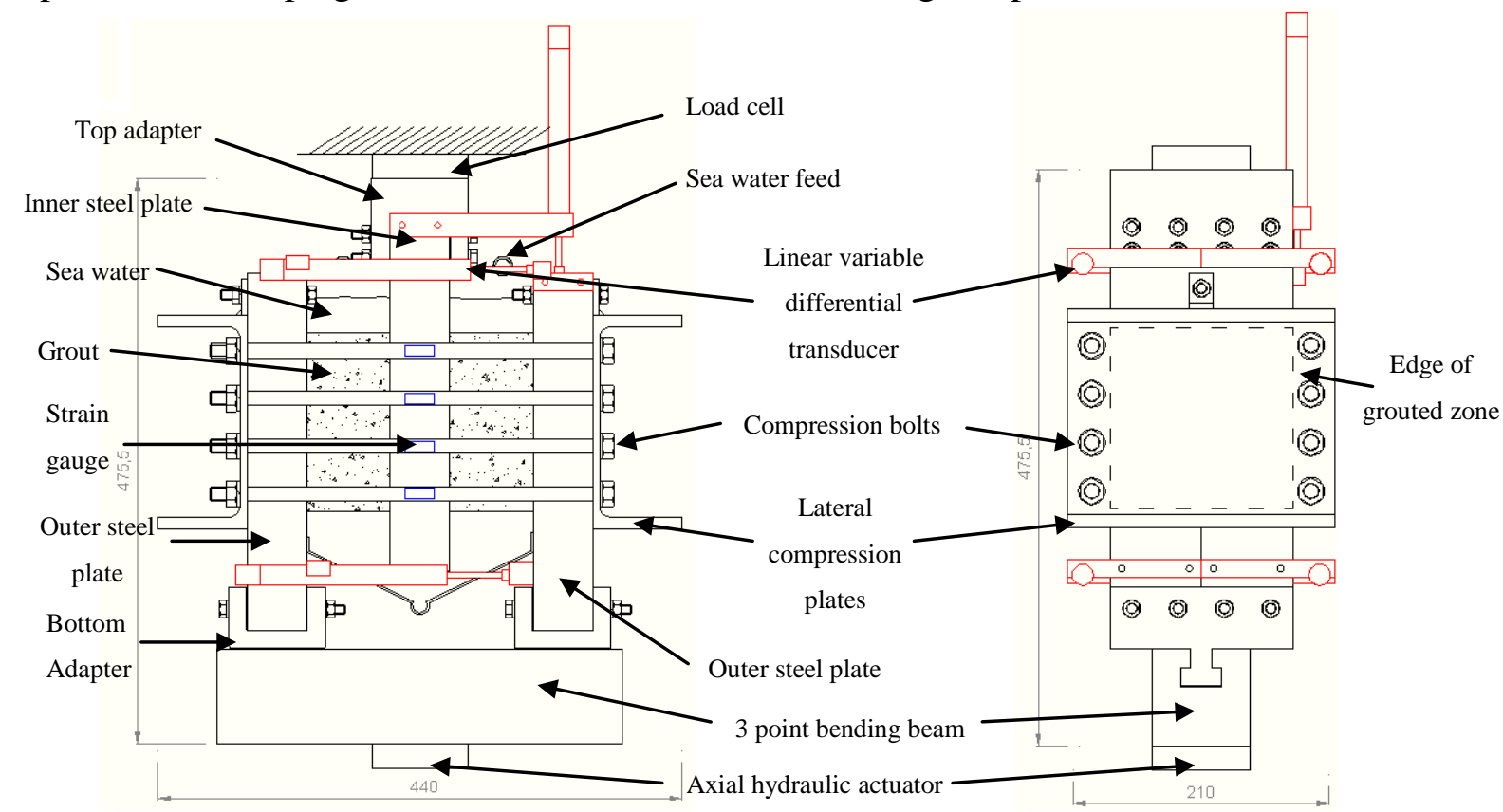

Figure 2: Experimental test arrangement

The compressive force can be varied and achieved by tightening the compression bolts. Strain gauges attached to these bolts will be calibrated with a load cell before testing commences, so the compressive stress on the grout can be derived for a given bolt strain. The bottom adapter and three point bending beam (shown in Fig. 2) have been designed to allow for the compressive loads to transfer wholly from the lateral plates to the grouted sample. 
The outer and inner steel plates along with the grout thickness have been chosen to be the same as design thicknesses used for operational OWECs, so that their stiffness is properly represented, and produced in the same manner as used offshore, which in subsequent testing the steel will be corroded to similar levels to ensure surface finish is representative. The steel and grout are also the same as generally used offshore, with 355NL steel and Densit Ducorit ${ }^{\circledR}$ S5 grout.

The test samples will be grouted in accordance with the procedures and the approval of the grout manufacturer, with test cubes taken to assess the strength of the grout. To ensure that the de-bond/cracking occurs at the interface between the inner steel plate and grout, shear keys will be used at the interface between the outer plates and grout; in addition de-bonding agents may be used on the inner plate surfaces. To represent the presence of sea water and the implications this may have on the grout-steel interaction, sea water will be fed onto the top surface of the grout and allowed to drain through the grout with the captured solution being filtered to determine particle distribution of any grout washout.

Linear Variable Differential Transformers (LVDT) will provide continual monitoring of the relative lateral displacement between the two outer plates, and therefore of any change in thickness of the grouted material if wear is occurring will be measured. The SCHENCK controller will log the axial displacements and load required to achieve these displacements. The lateral compression bolt strain will be recorded via the same data logger as the displacement sensors. This will ensure sufficient numerical data acquisition of the interaction of the steel grout surfaces. Visual indicators will also be acquired through periodic photography of the test samples and accumulated debris along with measurements of the grout and steel profile.

\subsection{Testing Procedure}

As part of the first stage of testing, it is required to ascertain the behaviour of the test equipment and sample and so a relatively harsh testing regime will be used to determine whether there is likely to be long term challenges caused by the grout wear failure mode. This testing regime will be relatively simple to maximise the information gained from testing and given the current lack of knowledge on the operational conditions seen by the grout the resultant conservativeness will not be detrimental to the quality of the results.

As part of this research, samples will be subjected to $10^{7}$ cycles at a frequency of $1 \mathrm{~Hz}$ and amplitude of $10 \mathrm{~mm}$, which will require about 4 months of testing for each sample. The number of cycles considered in this study is representative of the design value for OWECs, while the frequency of $1 \mathrm{~Hz}$ has been provisionally chosen to avoid a significant increase in the temperature due the heat generated from the friction of the two surfaces, which in turn is likely to affect the material properties of the samples. A temperature transducer will be included on the inner steel plate to monitor this temperature. The amplitude has been determined from available monitoring data collected from a representative OWEC structure, where an average total displacement of about $10 \mathrm{~m}$ per day has been recorded. If the individual small displacements of a magnitude of around $1 \mathrm{~mm}$ are summed over the day, the total relative displacement of $10 \times 365 \times 20=73,000 \mathrm{~m}$ has been assumed for each fatigue testing, which corresponds to an amplitude of $7.3 \mathrm{~mm}$, plus an allowance of $2.7 \mathrm{~mm}$ for machine tolerances, for the $10^{7}$ cycles.

The testing will commence with initial de-bonding of the grout from the steel inner plate by progressively increasing the axial load while a minimum compression of the plates is applied. After the initial de-bond, the grout will be inspected to determine its suitability to continue testing, ensuring large scale fracture has not occurred within the grout itself as it is relatively 
unconfined when compared to grout annulus it simulates. Provision has been made to contain the grout during de-bonding and / or aid failure along the steel / grout surfaces on the inner steel plate. If the de-bond has occurred as required the compression plate bolts will then be progressively tightened till a representative compressive stress of $1 \mathrm{MPa}$ is achieved.

Testing will then commence with $1 \mathrm{MPa}$, with increments in compressive stress every $1.5 \times$ $10^{7}$ cycles. During operation it is likely that the compressive force will diminish as the grout wears due to the nature of the test setup, and therefore regular checks of the bolt strain gauge readings will be required to determine how often the compression plate bolts will need tightening to obtain the desired lateral-compressive force. Daily checks will be made of the test equipment with visual indicators being recorded at the same time. This linear damage assumption of an increasing loading level regime will prove to be conservative as an increasing loading regime order has been shown to reduce fatigue lives over a decreasing order of loadings stress magnitudes (Grünberg et al., 2005).

The limitations in terms of initial assumptions on the relationship between the point of displacement occurring and the stress level experienced by the grout of this first round of testing will be addressed in future work if the grout testing indicates that grout wear could be a concern. A second round of testing will be undertaken that will have displacements and compressive forces based on offshore monitoring data from the OWEC grouted connection that is being experimentally modelled by E.ON. This data is currently being received and once processed it is hoped that a better understanding of the long term behaviour of the grouted connection under offshore operational conditions can be obtained. The ongoing offshore monitoring should enable validation of current finite element models of the grouted connection, therefore allowing a relationship between the loading experienced by the OWEC and the stress within the grout and surrounding steel structure to be derived along with the corresponding displacement experienced. This will enable statistical on site wind speed data to determine the displacement and stress profiles experienced by the steel/grout interface over the life of the connection and therefore an appropriate axial and lateral compression loading waveforms can be tested through the incorporation of an additional lateral hydraulic actuator to the proposed test setup.

\section{Conclusions}

Unexpected settlements have occurred in large diameter grouted connections for offshore wind turbines due to a limited understanding of the limits of previously used design codes and the complex material interaction for a system that experiences a high number of stress cycles. Work within the industry has been undertaken to try and understand these interactions and address the consequences of the settlements, but little research has been undertaken to understand the long term behavior under conditions that are representative of the operational conditions experienced by the grout. As such the testing arrangement proposed in this paper is to be undertaken to determine the effect of these conditions on the grout and to provide input to foundation integrity assessments.

\section{References}

[1] Det Norske Veritas (2010), Summary Report from JIP on the Capacity of Grouted Connections in Offshore Wind Turbine Structures, Det Norske Veritas, Norway.

[2] American Petroleum Institute (2000), Recommended Practice for Planning, Designing and Constructing Fixed Offshore Platforms - Working Stress Design, API RP-2A-WSD, 21st Edition, American Petroleum Institute, USA. 
$10^{\text {th }}$ International Conference on Advances in Steel Concrete Composite and Hybrid Structures Singapore, 2 - 4July 2012

[3] International Organization for Standardization (2007). EN ISO 19902 , Petroleum and natural gas industries - Fixed steel offshore structures, CEN - European Committee for Standardization, Brussels, Belgium.

[4] International Electrotechnical Commission (2005). IEC 61400-3, Design requirements for offshore wind turbines. International Electrotechnical Commission, Geneva, Switzerland.

[5] Germanischer Lloyd (2005). 'Guideline for the Certification of Offshore Wind Turbines,' Germanischer Lloyd WindEnergie GmbH, Heidorn Druckerei und Verlag, Uetersen/ Germany.

[6] Det Norske Veritas (2004). Offshore Standard DNV-OS-J101 - Design of Offshore Wind Turbine Structures, Det Norske Veritas, Høvik, Norway.

[7] Anderson, S. and Peterson, P. (2004). Structural Design of Grouted Connection In offshore Steel Monopile Foundations, Global Windpower.

[8] Klose, M., Faber, T., Schaumann, P. and Lochte-Holtgreven, S., (2008). Grouted Connections for Offshore Wind Turbines, International Offshore and Polar Engineering Conference, ISOPE, pp. 425-430.

[9] Anders, S. and Lohaus, L. (2008). Optimized High Performance Concrete in Grouted Connections. London: Taylor and Francis Group.

[10] Schaumann, P. and Wilke, F. (2005). Offshore Grouted Joints, GIGAWIND Symposium Offshore Windenergie, 2005.

[11] Lotsberg, I. (2010). Developments of Grouted Connections in Mono-pile Foundations. IABSE Seminar, Copenhagen, DNV.

[12] Billington, C. and Tebbett, I. (1980). The Basis for New Design Formulae for Grouted Jacket to Pile Connections, Offshore Technology Conference, Houston, USA 1980.

[13] Lamport, W. and Jirsa, J. (1986). Grouted Pile-to-Sleeve Connection Test. PMFSEL Report No. 86-7, Department of Civil Engineering, University of Austin, Texas, USA.

[14] Schaumann, P. and Keindorf, C. (2008). Hybrid Towers for Offshore Wind Energy Converters, International Offshore and Polar Engineering Conference, 2008, ISOPE, pp. 431-440.

[15] FIP-CEB (1990). High strength concrete - State of the art report, Bulletin d'Information No. 197, EuroInternational Committee for Concrete, Chameleon Press, London.

[16] Schaumann (2007). Design of Large Diameter Hybrid Connections Grouted with High Performance Concrete, Proceedings of the Seventeenth International Offshore and Polar Engineering Conference ISOPE 2007, Lisbon, Portugal, July 1-6, pp. 340 - 347.

[17] Grünberg, J., Göhlmann, J. and Ertel, C. (2005). Concrete Foundations for Offshore wind Energy Converters Subjected to Fatigue Loading, Copenhagen Offshore wind 2005.

[18] Schaumann, P., Lochte-Holtgreven, S., Lingaard, M., Lohaus, L. and Lindschulte, N. (2010) Durchrutschende Grout-Verbindungen in OWEA - Tragverhalten, Instandsetzung und Optimierung. Stahlbau,Vol. 79, pp. 637-647.

[19] Berndt, M. (2010). Strength and Permeability of Steel Fibre Reinforced Grouts, Construction and Building Materials, Vol. 24, pp. 1768-1772.

[20] Veludo, J., Julio, E. and Dias-da-Costa, D. (2012), Compressive Strength of Micropile to Grout Connectons, Construction and Building Materials, Vol. 26, pp. 172-179.

[21] Det Norske Veritas (2011). Testing of Grouted Connections Subjected to Static Axial Load and Dynamic Sliding. Det Norske Veritas, Norway. 